\title{
QUALIDADE DO AR NA FAVELA PARAISÓPOLIS, SP, E POSSIVEIS IMPLICAÇÕES À SAÚDE
}

\author{
Edelci Nunes da Silva ${ }^{1}$ \\ Célia Pesquero² \\ Helena Ribeiro ${ }^{3}$ \\ João Vicente Assunção 4
}

\begin{abstract}
Resumo: O crescimento da população favelada no município de São Paulo, o adensamento das construções existentes no interior da favela de Paraisópolis e a alta prevalência de doenças respiratórias em crianças ali vivendo, motivaram o presente estudo. Buscou-se verificar se a poluição do ar seria fator agravante. A pesquisa analisou a qualidade do ar na favela de Paraisópolis, situada no distrito de Vila Andrade, ao sul do bairro do Morumbi. Mediram-se parâmetros de poluição atmosférica (PTS, $\mathrm{PI}, \mathrm{NO}_{2}$ ) na favela, entre 15 e 31 de julho de 2003. Os dados de $\mathrm{PI}$ foram comparados com os dados das estações da CETESB, de Pinheiros e de Santo Amaro, localizadas próximas à área de estudo. Verificou-se que a poluição do ar não consistiu fator agravante na favela.
\end{abstract}

Palavras Chave: Poluição atmosférica; Favela; São Paulo; Paraisópolis.

\section{Introdução}

A cidade de São Paulo apresenta características singulares. Constitui uma das maiores manchas urbanas do mundo, situada sob o Trópico de Capricórnio, em domínio tropical úmido, na fachada oriental da América do Sul, em um planalto com $750 \mathrm{e}$ 800 metros acima do nível do mar e cerca de $50 \mathrm{~km}$ (em linha reta), da costa Atlântica. Seu crescimento baseou-se em altas taxas de incremento demográfico, grande concentração econômica e uma profunda defasagem entre as necessidades da população e a capacidade de atendimento dos serviços ofertados. A lógica de construção da cidade passou pelo deslocamento das centralidades, associado à exclusão territorial dos mais pobres, com o incremento da favelização e periferização (PMSP, 2004).

A favela Paraisópolis está situada no distrito de Vila Andrade, região Sudoeste do município de São Paulo, ao sul do Morumbi. Ela ocupa 85 hectares dos 1030 hectares do distrito, correspondendo a 8,2\% de sua área.

Estima-se que a população de Paraisópolis ultrapasse 30.000 habitantes (SEHAB/DIAGONAL URBANA, 2002), sendo a segunda maior favela da cidade em população. $O$ maior crescimento populacional deu-se, contudo, nas décadas de 1980 e 1990, principalmente por dois motivos: 1) a crise econômica instalada no Brasil nessas décadas e 0 conseqüente empobrecimento da população de uma forma geral e, em particular nos grandes centros urbanos, aliada à falta de políticas públicas de moradia voltadas à população de baixa renda; e 2) as ações pontuais de desfavelamento de outras áreas nobres da cidade ocorridas nas gestões Paulo Maluf e Celso Pitta, como a desapropriação das favelas do Real Parque e da Av. Águas Espraiadas, levaram ao aumento da demanda por moradias na favela Paraisópolis pelas pessoas desapropriadas (BRANT, 1989; ROLNIK et al., 1990; TASCHNER, 1999; TORRES et al, 2003, BALTRUSIS, 2000).

O Censo IBGE/2000 apontou 11.823 domicílios na favela de Paraisópolis, sendo que 10.045 domicílios são ocupados (SEHAB/DIAGONAL URBANA 2002). Em poucos anos, Paraisópolis viu o número de construções aumentar e tomar os espaços livres - aqueles anteriormente ocupados por vegetação ou desocupados, por serem menos propícios à ocupação habitacional.

\footnotetext{
${ }^{1}$ Mestre em Saúde Pública pela USP, professora de Climatologia da Faculdade Tereza Martin, enunes@usp.br

${ }^{2}$ Doutora em Química pela USP, pesquisadora e técnica do Laboratório de Qualidade do Ar da FSP/USP, celiapes@usp.br

${ }^{3}$ Professora titular do Departamento de Saúde Ambiental da FSP/USP, lena@usp.br

${ }_{4}^{4}$ Professor Doutor do Departamento de Saúde Ambiental da FSP/USP, janya@usp.br
} 
Desse processo, porém, ocorre 0 aumento das áreas já construídas, com ocupação das áreas menos propícias a esta finalidade, ou seja, aquelas de maior declividade, na beira dos córregos ou sobre eles.

Com isso, há sobrecarga da já precária infra-estrutura instalada, há redução de espaços livres e da vegetação existente, aumento de problemas ligados ao saneamento, como a sobrecarga com os esgotos domésticos nos córregos e aumento da produção de lixo.

A densidade demográfica na favela é, segundo os dados do censo IBGE/2000, de 520 habitantes por hectare. Porém, estudo de densidade realizado pela SEHAB/DIAGONAL URBANA (2002) indicou taxas de densidade ainda mais altas em seu interior: em $46,14 \%$ do território as taxas estão acima dos $600 \mathrm{hab} / \mathrm{ha}$ e, em alguns trechos, essa taxa pode ficar acima dos $1000 \mathrm{hab} / \mathrm{ha}$.

Comparando esses dados com os da densidade demográfica do distrito de Vila Andrade, 72,2 habitantes por hectare, e do Morumbi, 30 habitantes por hectare, ficam claros os contrastes e a disparidade no uso do solo urbano nessa região de São Paulo.

Em outras palavras, enquanto as áreas já precárias das favelas sofreram um incremento de sua população e das construções, em proporções bastante elevadas, as áreas do entorno tiveram um crescimento menor ou até mesmo um decréscimo de sua população. Dados da Secretaria de Planejamento Urbano mostram que, entre 1991 e 2000, o distrito de Vila Andrade teve uma taxa de crescimento de $6,28 \%$ e 0 distrito do Morumbi teve uma taxa de crescimento de $-1,61 \%$, ou seja, houve redução de sua população.

Dessa forma, os moradores em áreas de favelas, além de se encontrarem altamente vulneráveis aos fatores de risco, sejam eles esporádicos ou sazonais, como, por exemplo, deslizamentos e enchentes, que ocorrem com as chuvas já que as construções estão em terreno de difícil ocupação, encontram-se também cotidianamente mais expostos a doenças.

\section{As condições de saúde da população de Paraisópolis}

Pesquisa realizada, em 1997, pelo IDEM, encontrou 16\% das crianças e $19 \%$ dos adultos doentes. O perfil epidemiológico das crianças de 0 a 1 ano mostrou que há uma grande prevalência de alergia $(55,2 \%)$, bronquite $(11,7 \%)$, pneumonia $(6,3 \%)$, sinusite $(5,6 \%)$, queimadura $(2,8 \%)$, parasitose $(2,2 \%)$, gripe e tosse $(1,7 \%)$ e diarréia $(1,5 \%)$.

0 perfil das crianças de 2 a 5 anos se altera um pouco, aparecendo a pneumonia em $22,6 \%$ dos casos, a bronquite em
$18,6 \%$, a parasitose em $9,3 \%$, a alergia em $8,8 \%$, a diarréia em $4,5 \%$, a deficiência em $3,6 \%$, a anemia em $3,5 \%$, a desnutrição em $3,2 \%$, a infestação em $3,1 \%$, e a asma em $3,1 \%$.

Nas crianças de 6 a 12 anos, as seis doenças de maior prevalência são: parasitose, cárie, alergia, asma, infestação, bronquite e diarréia. Desnutrição, fraturas, pneumonia, sinusite e queimadura aparecem com menor incidência.

Um trabalho comparativo entre o perfil de internações hospitalares, do Sistema Único de Saúde, no município de São Paulo e na favela de Paraisópolis para 0 ano de 2001 mostrou que a taxa de internação é mais alta em Paraisópolis (419/10.000) do que no município de São Paulo (394/10.000), ou seja, 6,3\% maior em Paraisópolis do que no município como um todo. As três primeiras causas mais freqüentes de internações são as mesmas para ambos, porém as demais causas mais freqüentes diferem de padrão. Há, por exemplo, na favela Paraísópolis, um número maior de internações por broncopneumonia em lactentes, em atendimento em Clínica Pediátrica, crise asmática e bronquiolite (PEDROSO, 2002).

Em ambos estudos, observa-se a grande incidência de doenças que geralmente relacionam-se a fatores atmosféricos, tais como as broncopneumonia e as alergias.

Este trabalho tem por objetivo verificar, em uma área de favela, na cidade de São Paulo, a influência do uso do solo nos parâmetros de poluição do ar. Ressalta-se que 0 sítio urbano de São Paulo, em bacia sedimentar circundada por áreas mais elevadas, favorece estagnação do ar, agravando os problemas decorrentes da concentração de poluentes.

\section{Material e Métodos}

As medições de Material Particulado Total em Suspensão (PTS), Material Particulado Inalável (PI) e Dióxido de Nitrogênio $\left(\mathrm{NO}_{2}\right)$ foram feitas utilizando-se equipamentos do Laboratório de Qualidade do Ar da Faculdade de Saúde Pública da USP.

Os amostradores ficaram localizados na Creche Centro Comunitário de Paraisópolis, situada à Rua Rudolf Lotze, no período de 15 de julho a 01 de agosto de 2003.

0 material particulado total em suspensão foi coletado usando um amostrador de grande volume Energética, de acordo com o método NBR 9547 da Associação Brasileira de Normas Técnicas (ABNT, 1993). As amostras foram coletadas em filtro de fibra de vidro ( $203 \times 254 \mathrm{~mm})$, durante 24 horas, nos dias: 15 a 17,21 a 24 e 28 a 31 de julho de 2003, com início e término de coleta em torno de 10 horas da manhã, a uma vazão de 1,14 a $1,40 \mathrm{~m}^{3} / \mathrm{min}$. Antes da primeira coleta 0 amostrador foi 
calibrado através de orifício e manômetro de coluna d'água em $\mathrm{U}$, segundo a recomendação do método. A massa de material particulado foi determinada gravimetricamente, através da pesagem dos filtros antes e após a amostragem, utilizando-se uma Balança analítica Mettler Toledo AG-204, com precisão de $0,1 \mathrm{mg}$. Antes da pesagem, os filtros foram estabilizados por 24 horas em dessecador com sílica gel, para remoção da umidade.

Simultaneamente à coleta do Material Particulado em Suspensão foram coletadas amostras de Material Particulado Inalável nos dias 15, 23 e 24, 28 a 31 de julho de 2003, usando um amostrador de grande volume Wedding de acordo com 0 método NBR 13412 (ABNT, 1995). As amostras foram coletadas durante 24 horas a uma vazão de 1,176 a 1,195 m3/min em filtro de fibra de vidro $(203 \times 254 \mathrm{~mm})$. Antes e após a coleta, 0 amostrador foi calibrado usando um manômetro de coluna d'água em $U$, segundo recomendação do método. Os filtros foram pesados antes e após a amostragem usando Balança analíica Mettler Toledo AG-204, com precisão de 0,1 mg. Antes da pesagem os filtros foram estabilizados em dessecador com sílica gel por 24 horas, para remoção da umidade. Os dados de PI de Pinheiros e Santo Amaro foram obtidos da rede automática da CETESB que utiliza radiação $ß$ (CETESB, 2003).

A concentração do dióxido de nitrogênio $\left(\mathrm{NO}_{2}\right)$ atmosférico foi determinada pelo método de Saltzman (WHO, 1976), utilizando um amostrador de gases Energética modelo Tri-gás. Foram feitas coletas nos dias 15 a 18, 21 a 24, 28 a 31 de julho e 01 de agosto de 2003, no período da manhã, horário das 10 às 11 horas e nos dias $17,21,23,28$ e 30 nos horários das 10 às 11 horas e das 16 às 17 horas. Foram utilizados dois borbulhadores com dispersor poroso, em série, contendo $20 \mathrm{~mL}$ de reagente absorvente ${ }^{1}$. A vazão de amostragem utilizada foi de aproximadamente 0,550 $\mathrm{L} / \mathrm{min}$, com tempo de coleta de 60 minutos. As amostras foram analisadas em espectrofotômetro Shimadzu modelo UV 1203, a $550 \mathrm{~nm}$, utilizando curva de calibração construída com cinco concentrações de solução padrão de nitrito de sódio.

\section{Qualidade do ar em Paraisópolis}

Durante três semanas, de 15/07/2003 a 01/08/2003, foram medidos dados de poluição do ar na favela Paraisópolis: Partículas Totais em Suspensão (PTS), Partículas Inaláveis (PI) e Dióxido de Nitrogênio $\left(\mathrm{NO}_{2}\right)$. Esse período correspondeu a meados do inverno, quando os níveis de poluentes normalmente são mais elevados, devido às condições atmosféricas que dificultam a dispersão (Tab. 1).

Os dias 21, 22, 23, 24 e 25 de julho apresentaram os valores mais elevados com relação aos poluentes PTS e PI. 0 $\mathrm{NO}_{2}$ apresentou valores mais elevados nos dias 16, 18, 23 a 25 de julho.

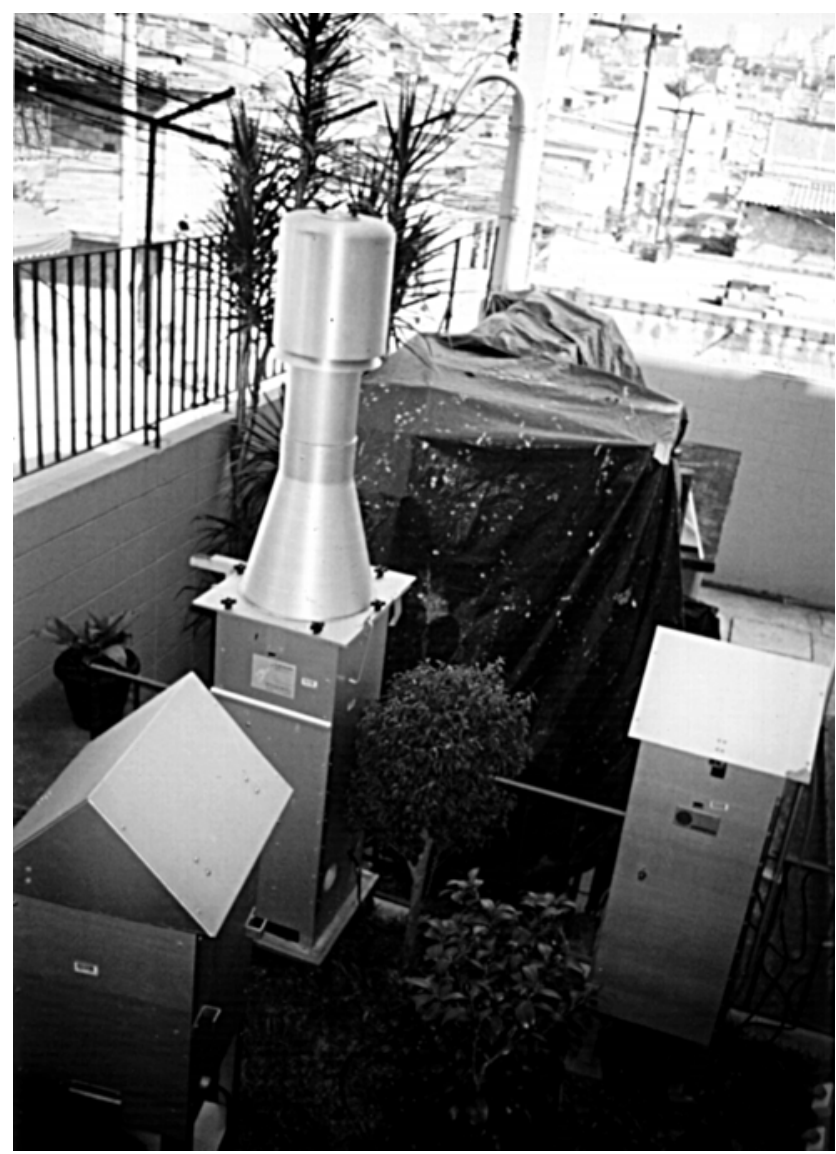

Figura 1 Amostradores de Poluentes PTS, $\mathrm{PI}, \mathrm{NO}_{2}$ na Creche do Centro Comunitário de Paraisópolis (Foto: João Vicente Assunção, julho de 2003).

Na primeira semana, os valores de PTS estiveram baixos e, nos dias 16 a 18 estiveram abaixo do padrão primário ${ }^{2}$ de 24 horas. Nos dias 21/22, 23/24 e 24/25, observa-se que os valores de PTS ultrapassaram o padrão primário de 24 horas;; nos dias 29/07 a 01/08 os valores estiveram acima do padrão primário anual (Fig. 2).

As Partículas Inaláveis foram medidas no dia $15 / 07$, sendo suas medidas retomadas no período entre $23 / 07$ e $01 / 08$. Os valores estiveram altos - acima do padrão primário anual -

${ }^{1}$ Solução a 0,002\% de dihidrocloreto de n-(1-naftil) etilenodiamina, 0,026M de ácido sulfanílico e 2,45M de ácido acético. 
somente nos dias 23, 24 e 25/07; no restante do período, os valores estiveram abaixo do padrão primário anual. Durante todo o período medido os valores não atingiram o padrão primário de 24 horas (Fig. 3).

Tabela 1 Resumo das concentrações $\left(\mu \mathrm{g} / \mathrm{m}^{3}\right)$.

\begin{tabular}{|c|c|c|c|c|}
\hline Data & $\mathrm{NO}^{2}$ manhã (1h) das 10 às 11 horas & $\mathrm{NO}^{2}$ tarde (1h) das 16 às 17 horas & PTS (24h) & PI (24h) \\
\hline $15 / 7 / 2003$ & 57,7 & & 105,6 & 31,4 \\
\hline $16 / 7 / 2003$ & 132,3 & & 66,3 & \\
\hline $17 / 7 / 2003$ & 45,4 & 67,7 & 70,5 & \\
\hline $18 / 7 / 2003$ & 107,2 & & & \\
\hline $21 / 7 / 2003$ & 72,0 & 45,4 & 265,6 & \\
\hline $22 / 7 / 2003$ & 93,6 & & 145,0 & \\
\hline $23 / 7 / 2003$ & 194,9 & 57,3 & 259,5 & 78,1 \\
\hline $24 / 7 / 2003$ & 131,9 & & 253,4 & 76,2 \\
\hline $25 / 7 / 2003$ & 131,4 & & & \\
\hline $28 / 7 / 2003$ & 64,0 & 61,9 & 78,6 & 19,2 \\
\hline 29/7/2003 & 84,0 & & 150,4 & 41,6 \\
\hline $30 / 7 / 2003$ & 73,6 & 38,2 & 129,0 & 40,8 \\
\hline $31 / 7 / 2003$ & 80,9 & & 94,2 & 27,9 \\
\hline $1 / 8 / 2003$ & 43,8 & & & \\
\hline MEDIA & $93,76\left(^{*}\right)$ & $54,1\left(^{*}\right)$ & $130,0(* *)$ & $45,0\left(^{*}\right)$ \\
\hline
\end{tabular}

Organização: Célia Pesquero/Edelci Nunes.

$\left({ }^{*}\right)$ Média Aritmética - $\left.{ }^{* *}\right)$ Média Geométrica.

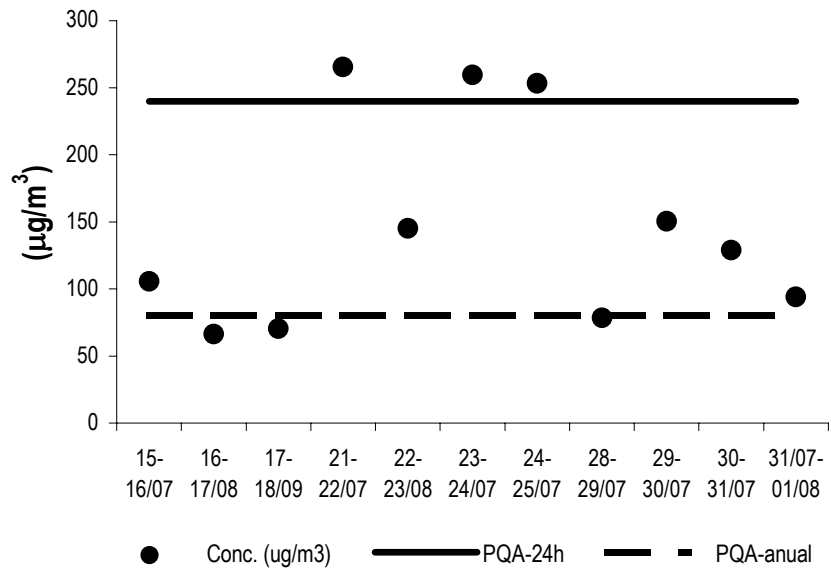

Figura 2 Partículas Totais em Suspensão, Paraisópolis, Município de São Paulo.

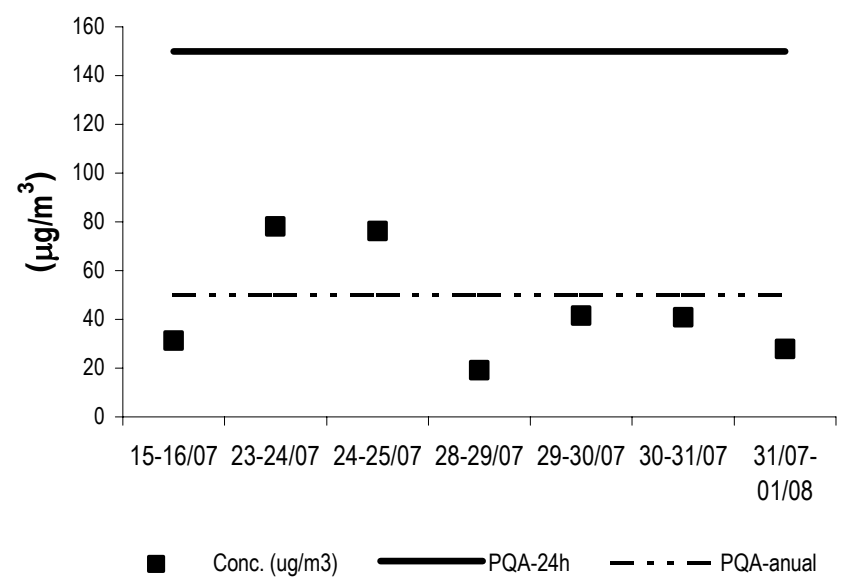

Figura 3 Partículas Inaláveis, Paraisópolis, Município de São Paulo.

\begin{abstract}
2 Padrões Primários de qualidade do ar são as concentrações de poluentes que, ultrapassadas, poderão afetar a saúde da população. Padrões Secundários de qualidade do ar são as concentrações de poluentes abaixo das quais se prevê o mínimo efeito adverso sobre 0 bem estar da população, assim como o mínimo dano à fauna, à flora, aos materiais e ao meio ambiente em geral (Resolução CONAMA No. 03/1990) Disponível em http://www.mma.gov.br/conama, acesso em 12/01/2004.
\end{abstract}

${ }^{3}$ Segundo a resolução CONAMA-003/28/06/1990 a concentração média não deve ser ultrapassada mais do que uma vez ao ano. 
0 dióxido de nitrogênio foi medido durante uma hora por dia, no período de 15/07 a 01/08. Em todo o período, os valores estiveram abaixo do padrão primário de 1 hora, como pode ser visto na Fig. 4. Em 5 dias do período medido, os valores estiveram acima do padrão primário anual na favela. A maior concentração desse gás ocorreu no dia 23/07, 194,85 $\mu \mathrm{g} / \mathrm{m}^{3}$. Os valores de $\mathrm{NO}^{2}$ medidos no período da tarde estiveram mais baixos do que aqueles medidos pela manhã, exceto no dia 17/07.

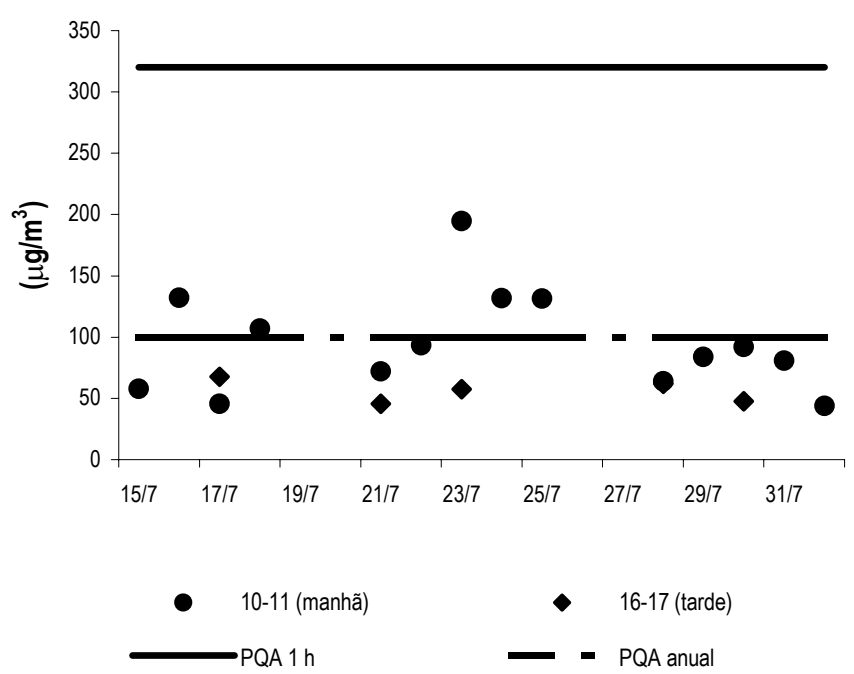

Figura 4 Dióxido de Nitrogênio $\left(u g / \mathrm{m}^{3}\right)$, Paraisópolis, Município de São Paulo.

Considerando a estrutura do índice de qualidade do ar da CETESB, dos quatorze dias de monitoramento da qualidade do ar na favela Paraisópolis, somente três dias podem ser considerados como de qualidade inadequada com relação ao poluente PTS. Nos outros dias a qualidade do ar esteve entre regular e boa. Com relação às partículas inaláveis (PI), o período monitorado apresentou-se com qualidade do ar regular e boa. Com relação ao $\mathrm{NO}^{2}$, a qualidade do ar na maior parte dos dias esteve boa.

\section{Discussão}

Desde que a poluição do ar se tornou causa de preocupação na cidade de São Paulo, no final dos anos 60, diferentes profissionais começaram a desenvolver estudos para avaliar seu impacto à saúde da população e os efeitos das medidas de controle adotadas. Estudos pioneiros foram feitos por variadas instituições e sem muita continuidade. Entretanto, a partir dos anos 90, um expressivo número de pesquisadores, ligados ao Laboratório Experimental de Poluição do Ar do Departamento de
Os dados de partículas inaláveis obtidos em Paraisópolis foram comparados com os dados medidos em duas estações da CETESB da cidade de São Paulo: a Estação de Santo Amaro e a Estação de Pinheiros, as mais próximas da área de estudo. Podese observar, na Fig. 5 que os valores de partículas inaláveis obtidos na favela foram inferiores aos valores de Santo Amaro e Pinheiros, mesmo na semana em que a concentração desse poluente ultrapassou o padrão primário anual.

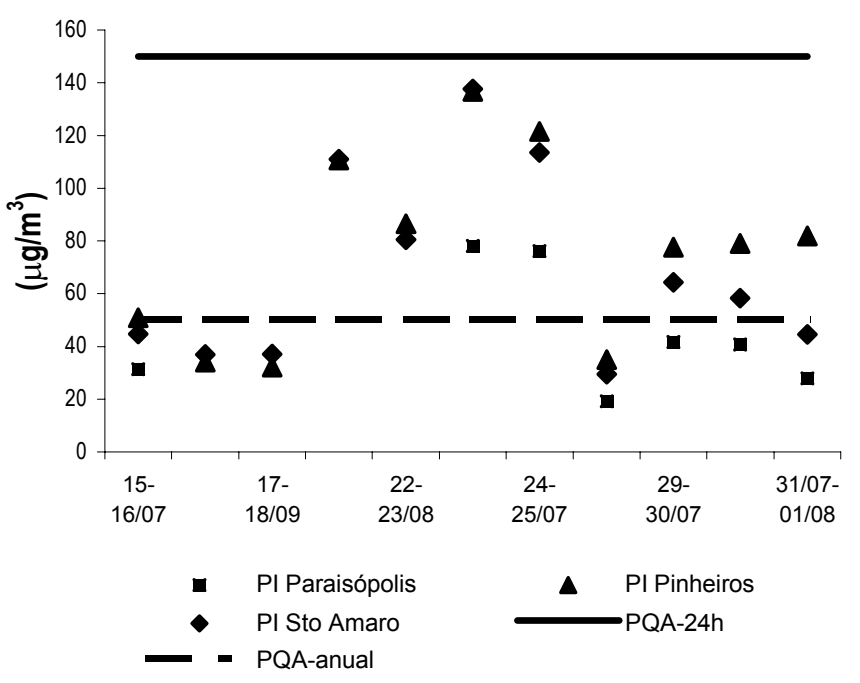

Figura 5 Comparação entre os dados de $\mathrm{PI}\left(u g / \mathrm{m}^{3}\right)$ em Paraisópolis e nas estações da CETESB, Santo Amaro e Pinheiros.

Patologia e ao Departamento de Medicina Preventiva da Faculdade de Medicina, assim como ao Departamento de Saúde Ambiental da Faculdade de Saúde Pública da Universidade de São Paulo, vem desenvolvendo estudos visando verificar possíveis correlações entre a poluição atmosférica urbana e agravos à saúde. De forma geral, estes estudos demonstraram existir uma influência da poluição atmosférica, sobretudo material particulado inalável (PI), na incidência e prevalência de doenças respiratórias em crianças e idosos (RIBEIRO e CARDOSO, 2003; SALDIVA et al., 1995; GOUVEIA e FLETCHER, 2000; FARHAT, 1999).

Os dados de poluição atmosférica medidos na favela de Paraisópolis não apontaram para uma sobrecarga de poluentes produzido na favela, pelo uso e ocupação do solo.

A qualidade do ar na favela Paraisópolis apresentou-se como regular e boa, na maior parte do período medido, embora 0 poluente PTS tenha se apresentado em concentrações mais elevadas, constituindo uma situação mais grave. Sua origem, muito provavelmente, se relaciona à falta de asfalto, à carência de 
varrição e umectação, ao grande número de obras e material de construção manuseado a céu aberto.

A concentração de partículas inaláveis foram inferiores as observadas nas estações de medição da CETESB, Santo Amaro e Pinheiros, indicando que a qualidade do ar na favela é melhor do que a qualidade do ar nestes dois pontos próximos a ela. Tal fato, muito provavelmente, deve-se à área de localização da favela de Paraisópolis.

TARIFA e ARMANI (2001) classificaram o clima desse setor do município de São Paulo como Clima Tropical de Altitude do Planalto Paulistano. Esta subunidade, segundo os autores, caracteriza-se por temperatura média anual que varia de $19,6^{\circ} \mathrm{C}$ a $19,3^{\circ} \mathrm{C}$, média anual das máximas, entre de $25,2^{\circ} \mathrm{C}$ a $24,9^{\circ} \mathrm{C}$ e média anual das mínimas, de $15,8^{\circ}$ a $15,5^{\circ} \mathrm{C}$. Os totais pluviométricos anuais oscilam entre $1250 \mathrm{~mm}$ e $1580 \mathrm{~mm}$.

Estes autores consideram que este setor da cidade apresenta condições razoáveis de dispersão de poluentes, variando em função da altura da camada de mistura. A situação topográfica da área favorece a drenagem noturna de ar frio, possibilitando a ocorrência de baixas inversões térmicas ( 50 a 200 m) sobre as várzeas e fundos de vale (TARIFA e ARMANI, 2001).

Ainda, segundo os mesmos autores, a área apresenta uma unidade climática urbana privilegiada pelo verde dos bairros Cidade Jardim e Morumbi "... a enorme área verde com densa arborização cria microclimas perfeitos para a reprodução da vida, tanto em nível biológico como social". Essa subunidade arborizada apresenta uma atenuação térmica de $2^{\circ}$ a $3^{\circ} \mathrm{C}$ da temperatura da superfície inferior em relação a algumas favelas dentro ou próxima a ela (TARIFA e ARMANI, 2001).

O Atlas Ambiental realizado pela Secretaria Municipal do Meio Ambiente apontou o Morumbi como segundo distrito da cidade com as melhores condições ambientais. 0 diagnóstico realizado considerou a cobertura vegetal $\left(\mathrm{m}^{2} / \mathrm{hab}\right)$, índice de desmatamento e a temperatura aparente da superfície para essa classificação. Dessa forma, o Morumbi encontra-se entre os quatro distritos, segundo o Atlas Ambiental, que apresentam de ótima a boa qualidade ambiental. Já o distrito de Vila Andrade (onde se insere a área estudo) é o $16^{\circ}$ no ranking e está classificado entre aqueles que apresentam qualidade ambiental de média a ruim ${ }^{4}$. Esta característica, provavelmente, deve-se ao fato da presença de favelas neste distrito. Segundo a Diagonal Urbana (2002), 64,7\% do distrito de Vila Andrade é composto por aglomerados sub-normais, enquanto que 0 distrito do Morumbi, por $18,7 \%$.

Dessa forma, neste setor da cidade, a ocupação do solo ocorreu de forma não homogênea e a paisagem é marcada pelas contradições do sistema sócio-econômico vigente. Podemos encontrar, nesta área, os enclaves de pobreza, que destoam da paisagem "nobre" desta área. Um desses enclaves corresponde à favela Paraisópolis.

Deve-se ressaltar que o período de medição dos poluentes atmosféricos correspondeu ao período de inverno que, na cidade de São Paulo, corresponde a um período desfavorável à dispersão da poluição devido às condições meteorológicas. Nesta época do ano, ocorrem freqüentemente inversões térmicas que dificultam a dispersão dos poluentes.

\section{Conclusões}

Pelos dados levantados no período não se pode considerar que a poluição atmosférica externa seja o fator mais agravante de doenças respiratórias na favela do que no restante da cidade. Os índices mais elevados de doenças respiratórias na área da favela, em relação ao total do município, muito provavelmente estão relacionados a condições inadequadas de moradia e outros fatores de risco tais como fumo dos pais, poluição interna, pior acesso a atendimento ambulatorial.

Contudo, esta pesquisa foi realizada no bairro do Morumbi, em São Paulo, que, considerado em mesoescala, possui melhor qualidade ambiental atmosférica (LOMBARDO, 1984; TARIFA e ARMANI, 2001, PMSP, 2003). É possível que, em bairros ou setores da cidade onde a atmosfera seja mais degradada, em mesoescala, os impactos em ambientes de favela sejam mais graves.

Os autores recomendam que medições em séries mais longas sejam feitas neste local e em outras regiões da cidade não cobertas pelas estações de monitoramento da Cetesb.

\section{Agradecimentos}

Ao Centro Comunitário Paraisópolis, onde os equipamentos foram instalados.

${ }^{4}$ Disponível em http://atlasambiental.prefeitura.sp.gov.br 
NUNES, E.; PESQUERO, C.R.; RIBEIRO, H.; ASSUNÇÃO, J.V. (2006). Air Quality in Favela Paraisópolis and Possible Health Effects. Revista do Departamento de Geografia, n. 18, p. 60-66.

Abstract: The population growth of slums in the municipality of São Paulo, the increased density in constructions inside the favela Paraisopolis and the high prevalence of respiratory diseases among children living in the area motivated this study. It aimed to verify if air pollution was a health risk factor. Air quality in the favela Paraisopolis, located at Vila Andrade district at the Morumbi area, was analyzed. Total suspended particles, Inhalable particles and Nitrogen dioxide parameters were measured during the period July 15 to July 31, 2003. Inhalable particles concentrations were compared to Pinheiro and Santo Amaro CETESB monitoring stations, located near the area of study. It was verified that air pollution did not represent an additional health risk factor.

Key words: Air pollution; Slums; São Paulo; Paraisópolis

Recebido em 14 de agosto de 2004, aceito em 2 de outubro de 2005.

\section{Referências}

ABNT - Associação Brasileira de Normas Técnicas. NBR 13412 (1995) Material Particulado em Suspensão na Atmosfera Determinação da concentração de Partículas inaláveis pelo Amostrador de Grande Volume acoplado a um Separador Inercial de Partículas. Jun 1995.

ABNT - Associação Brasileira de Normas Técnicas. NBR 9547 (1993) Material particulado em suspensão no ar ambiente Determinação da concentração total pelo método do Amostrador de Grande Volume. Fev 1993.

BALTRUSIS N. (2000) A dinâmica no mercado imobiliário informal na Região Metropolitana de São Paulo, um estudo de caso nas favelas de Paraisópolis e Nova Conquista. Campinas (dissertação de mestrado - Faculdade de Arquitetura e Urbanismo da PUC).

CETESB (2002) Relatório de Qualidade do Ar 2002. CETESB. Disponível em <http://www.cetesb.sp.gov.br>, último acesso em 09/01/2004.

FARHAT, S. C. L. (1999) Efeitos da Poluição Atmosférica na Cidade de São Paulo sobre doenças do trato respiratório inferior em uma população pediátrica. Tese de doutorado. Faculdade de Medicina. Universidade de São Paulo, 180p.

GOUVEIA, N.; FLETCHER, T. (2000) Time series analysis of air pollution and mortality: effects by cause, age and socioeconomic status. Journal Epidemiology Community Health, 54: 0-6.

IBGE - INSTITUTO BRASILEIRO DE GEOGRAFIA E ESTATÍSTICA. (2000) Censo Demográfico 2000. <http://www.ibge. gov.br>, último acesso em 28/10/2003.

IDEM - INSTITUTO DIADEMA DE ESTUDOS MUNICIPAIS. (1997) - Censo de Morbilidade do Hospital Israelita Albert
Einstein - Paraisópolis. [não publicado].

LOMBARDO, M. (1985) Ilha de calor nas metrópoles: o exemplo de São Paulo. Hucitec. São Paulo.

PEDROSO M. M. (2002) Comparação entre o perfil das internações hospitalares no Sistema Único de Saúde no Município de São Paulo e na favela de Paraisópolis (2001) São Paulo (Trabalho de conclusão de curso. PUC/SP, mimeo).

PMSP - PREFEITURA DO MUNICÍPIO DE SÃO PAULO. Atlas ambiental. Disponível em <www.atlasambiental.sp.gov.br>, acesso em 28/11/2003.

PMSP - PREFEITURA DO MUNICÍPIO DE SÃO PAULO (2004) Atlas ambiental do Município de São Paulo. Secretaria Municipal do Verde e Meio Ambiente. 266p.

RIBEIRO, H.; CARDOSO, M. R. A. (2003) Air pollution and children's health in Sao Paulo (1986-1998). Social Science and Medicine 57, 2013-2022.

SALDIVA, P. H. et al. (1995) Air pollution and mortality of elderly people: a time series study in São Paulo, Brazil. Arch. Environ. Health, 50 (2): 159-163.

SEHAB - SECRETARIA MUNICIPAL DE HABITAÇÃO E DESENVOLVIMENTO URBANO E DIAGONAL URBANA (2002) Diagnóstico Socioeconômico e Urbanístico Ambiental das comunidades de Paraisópolis, Jardim Colombo e Porto Seguro. [CDROM].

TARIFA, J. R.; ARMANI, G. (2001) Os Climas Urbanos. In TARIFA, J. R.; AZEVEDO, T.R. Os Climas na Cidade de São Paulo. GEOUSP 4, Pró-Reitoria de Cultura e Extensão Universitária. Universidade de São Paulo. 199 p. 